\title{
COMPARATIVE STUDY OF LRINEC SCORE: PROCALCITONIN AND LRINEC SCORE: C-REACTIVE PROTEIN IN PREDICTING DURATION OF HOSPITAL STAY AND SEVERITY IN NECROTISING FASCIITIS
}

\author{
Manoj Gowda Avalahalli, Pavan Kumar Muniraja², Mohammed Suhail Khalid ${ }^{3}$, Kavitha Kaverappa4, Lakshmi Devaraj ${ }^{5}$, Akshay Rao ${ }^{6}$
}

${ }^{1}$ Post Graduate, Department of Internal Medicine, M. S. Ramiah Medical College.

2 Associate Professor, Department of Internal Medicine, M. S. Ramiah Medical College.

${ }^{3}$ Post Graduate, Department of Internal Medicine, M. S. Ramiah Medical College.

4 Post Graduate, Department of Obstetrics and Gynaecology, M. S. Ramiah Medical College.

5 Post Graduate, Department of Biochemistry, M. S. Ramiah Medical College.

${ }^{6}$ Assistant Professor, Department of Internal Medicine, M. S. Ramiah Medical College.

\section{ABSTRACT}

\section{BACKGROUND}

Laboratory Risk Indicator for Necrotizing Fasciitis (LRINEC score) is a simple laboratory tool used to distinguish between Necrotizing Soft-Tissue Infections (NSTI) and other soft-tissue infections. A LRINEC score of $\geq 6$ is considered as denoting a high risk of necrotizing fasciitis. A very high LRINEC score might also be associated with mortality and other outcomes of patients with NSTI.

\section{METHODS}

A review of the medical charts of patients was carried out in a tertiary academic Centre. All adult patients with necrotizing softtissue infections from 2010 to 2011 were selected and LRINEC scores were calculated for each patient. The enrolled patients had sufficient information to determine the LRINEC score. Serum Procalcitonin (PCT) was used in place of serum C-Reactive Protein (CRP) to improve the efficacy of LRINEC score. Serum PCT was considered positive if the value was $>0.56 \mathrm{ng} / \mathrm{mL}$. LRINEC score-PCT and LRINEC score-CRP were compared in predicting duration of hospital stay and severity.

\section{RESULTS}

In this study of 50 patients $64 \%$ of them were males, majority of the patients were between the age group of $40-80$ years. LRINEC score PCT had better predictability for severity and duration of hospital stay when compared to LRINEC score with CRP. Pearson correlation of LRINEC score PCT vs LRINEC score, CRP was statistically significant with LRINEC score, PCT having $30 \%$ of patients with longer duration of hospital stay in comparison to LRINEC score CRP which had $12 \%$.

\section{CONCLUSION}

LRINEC score: PCT had better probability in predicting severity and duration of hospital stay when compared to LRINEC score: CRP.

\section{KEYWORDS}

Necrotizing Soft-Tissue Infection; LRINEC Score; CRP; PCT; Duration of Stay and Severity.

HOW TO CITE THIS ARTICLE: Avalahalli MG, Muniraja PK, Khalid MS, et al. Comparative study of LRINEC score: procalcitonin and LRINEC score: C-reactive protein in predicting duration of hospital stay and severity in necrotising fasciitis. J. Evolution Med. Dent. Sci. 2016;5(51):3248-3251, DOI: 10.14260/jemds/2016/754

\section{INTRODUCTION}

Necrotizing soft-tissue infection is defined as infections of any of the layers within the soft tissue compartment (Dermis, subcutaneous tissue, superficial fascia, deep fascia or muscle) that are associated with necrotizing changes. It was first described by Jones in 1871 and termed as "hospital gangrene." Following which multiple descriptions of NSTI have been published and a wide number of terms, definitions and classifications have been used.(1-5) In 1951, Wilson coined the term "necrotizing fasciitis" to encompass some of these infections. (6)

Though incidence of NSTI is low, NSTIs occur often enough that surgeons, physicians, infectious diseases specialists and others will encounter at least one patient with NSTI during their practice.(7)

Financial or Other, Competing Interest: None.

Submission 10-05-2016, Peer Review 04-06-2016,

Acceptance 10-06-2016, Published 24-06-2016.

Corresponding Author:

Manoj Gowda Avalahalli,

\#65 Avalahalli S. N. Halli,

Post Yelahanka Hobli

Bangalore-560064.

E-mail: manoj.gowda1@gmail.com

DOI: $10.14260 /$ jemds/2016/754
Earlier diagnosis and expedited treatment of NSTI was essential for improving outcome and decreasing the mortality.

Establishing the diagnosis of NSTI is difficult. For early diagnosis a physician should have high index of suspicion. The most important discriminative factor to be established in patients with soft-tissue infection is the presence of a necrotizing component. This will confirm NSTI and will identify patients that require surgical debridement as per definition.

True risk factors for NSTI have not been identified. Some of the conditions that are commonly associated with NSTI are injection drug use and chronic comorbidities (e.g. diabetes mellitus, immune suppression and obesity).(8-10) Patients that have any of these conditions and present with soft-tissue infection should be evaluated to rule out NSTI.

Large published series show that aetiology is unknown in $\geq 20 \%$ of patients with NSTI. These patients are considered to have idiopathic NSTI.(11-13) It has been observed that cases of NSTI without a recognized precipitating factor are more likely to be caused by group A streptococcal infection. Recently, NSTI without a recognized precipitating factor has also been identified with community-acquired methicillin-resistant staphylococcal infection.(14) 
Initial clinical features like swelling, erythema, pain and tachycardia help to raise the index of suspicion for NSTI. As the infection progresses, more typical signs and symptoms can be observed. These include tense oedema around the area of compromised skin, pain disproportionate to appearance, skin discoloration, blisters/bullae, necrosis, crepitus and/or subcutaneous gas. Systemic findings include tachycardia, fever, hypotension and shock. These findings are typical and fairly specific for NSTI. But their sensitivity is low and is present in only $10 \%-40 \%$ of patients with NSTI.(15-17)

LRINEC score is a simple laboratory tool used to distinguish between Necrotizing Soft-Tissue Infections (NSTI) and other soft-tissue infections. A LRINEC score of $\geq 6$ is considered as denoting a high risk of necrotizing fasciitis. LRINEC consists of six laboratory variables that include CRP, total white cell count, haemoglobin, serum sodium, serum creatinine and serum glucose as shown in Table 1.

C-Reactive Protein (CRP) is a pentameric protein found in blood plasma, whose levels rise in response to inflammation. It is an acute-phase protein of hepatic origin that increases following interleukin- 6 secretion by macrophages and T cells. PCT, a protein that consists of 116 amino acids, is the peptide precursor of calcitonin, a hormone that is synthesized by the parafollicular $\mathrm{C}$ cells of the thyroid and involved in calcium homeostasis. PCT arises from endopeptidase-cleaved preprocalcitonin. The reference value of procalcitonin in adults is $0.15 \mathrm{ng} / \mathrm{mL}$ or less. In healthy adults, the reference range of procalcitonin is below the level of detection. The halflife of procalcitonin is 25-30 hours (Not significantly altered in individuals with renal dysfunction).

The reported diagnostic accuracy of PCT and CRP for the diagnosis of bacterial infections has varied across studies. Hence, in our study we are comparing LRINEC score - PCT with LRINEC score - C-reactive protein in predicting duration of hospital stay and severity in necrotizing fasciitis.

\begin{tabular}{|c|c|}
\hline LRINEC Score with CRP & LRINEC Score with PCT \\
\hline CRP & PCT \\
Positive- 4 & Positive- 4 \\
Negative- 0 & Negative -0 \\
\hline WBC count cells per $\mathrm{mm}^{3}$ & WBC count cells per mm3 \\
$15-25=0$ & $<15=0$ \\
$>25=2$ & $15-25=1$ \\
Haemoglobin g/dL & $>25=2$ \\
$>13.5=0$ & Haemoglobin $\mathrm{g} / \mathrm{dL}$ \\
$11-13.5=1$ & $>13.5=0$ \\
$<11=2$ & $<11=2.5=1$ \\
$\geq 135=0$ & $\geq 135=0$ \\
$<135=1$ & $<135=1$ \\
\hline Sodium level mmol/L & Sodium level mmol/L \\
$\leq 1.6=0$ & Creatinine level mg/dL \\
$>1.6=1$ & $>1.6=0$ \\
Creatinine level mg/dL & Glucose level mg/dL $=1$ \\
\hline $180=0$ & $\leq 180=0$ \\
$>180=1$ & $>180=1$ \\
\hline Gable 1: LRINEC Score-PCT and LRINEC Score-CRP \\
\hline
\end{tabular}

\section{METHODOLOGY}

This was a retrospective, observational cohort study. An electronic search was made of all adult patients $(>18$ years of age) admitted to hospital through the Emergency Department (ED) medical/surgical OPD having a discharge diagnosis of necrotizing fasciitis. The study centre is a Tertiary Academic Centre. After our Institutional Review Board approved the study, a search was made from the hospital medical record database during 1-year 7-month period (May 2010 to December 2011).

We included consecutive patients with a discharged diagnosis of necrotizing fasciitis by International Classification of Diseases, Ninth Revision (ICD-9) code (72886). The discharge diagnosis of necrotizing fasciitis was made by medical/surgical attending physicians; then it would be coded as 72886 according to ICD-9 by the medical data managers. Patients were excluded if they were $\leq 18$ years old, transferred from other institutions or had an uncertain LRINEC score that we could not determine to be $\geq 6$. For patients with multiple admissions due to necrotizing fasciitis, only the first admission was recorded.

Age, gender, comorbidities, clinical symptoms/signs, site and aetiology of infection, Emergency Department (ED) triage vital signs, laboratory findings at the time of admission, medication being taken at the time of admission and microbiology of wound and blood cultures were reviewed. The LRINEC score was calculated for each case based on points assigned for each of six laboratory variables at the time of patient presentation including CRP, total white cell count, haemoglobin, serum sodium, serum creatinine and serum glucose. In this study, serum PCT was used in place of serum CRP to improve the efficacy of LRINEC score. Serum PCT was considered positive if values were $>0.56 \mathrm{ng} / \mathrm{mL}$. Patients were classified into three groups: low risk group (LRINEC score $\leq 5$ ), moderate risk group (LRINEC score 6-7) and high risk group (LRINEC $\geq 8$ ).

\section{STATISTICAL METHODS}

Descriptive and inferential statistical analysis has been carried out in the present study. Results on continuous measurements are presented on Mean ? SD (Min-Max) and results on categorical measurements are presented in Number (\%). Significance is assessed at $5 \%$ level of significance.

Analysis of Variance (ANOVA) has been used to find the significance of study parameters. Chi-square/Fisher Exact test has been used to find the significance of study parameters on categorical scale between groups. Pearson correlation between study variables is performed to find the degree of relationship.

\section{Classification of Correlation Co-Efficient (r)}

- $\quad$ Suggestive significance (P value: $0.05<\mathrm{P}<0.10$ ).

- Moderately significant ( $\mathrm{P}$ value: $0.01<\mathrm{P}<0.05$ ).

- $\quad$ ** Strongly significant (P value: $\mathrm{P}<0.01$ ).

\section{Statistical Software}

The Statistical software namely SAS 9.2, SPSS 15.0, Stata 10.1, MedCalc 9.0.1, Systat 12.0 and R environment ver. 2.11.1 were used for the analysis of the data and Microsoft Word and Excel have been used to generate graphs and tables.

\section{RESULTS}

In this study of 50 patients $64 \%$ of them were males, majority of the patients were between the age group of 40-80 years as shown in Table 2. Majority of patients with necrotizing fasciitis had lower limb involvement, overall $86 \%$ with $44 \%$ involving left lower limb only and 36\% involving right lower limb only 
and $6 \%$ had both the lower limb involved; $50 \%$ patients had positive serum PCT in comparison to CRP where only $24 \%$ had positive CRP as shown in Table 3; $54 \%$ belonged to moderate and high risk LRINEC score PCT compared to LRINEC score CRP which was $38 \%$ which was statistically significant (p value 0.04$) ; 34 \%$ of the patients had positive pus culture from the wound and only $4 \%$ of the patients had positive blood culture. Maximum duration of hospital stay being 30 days and minimum duration of stay was 5 days and the mean duration of stay was $(9.70 \pm 4.02)$ in LRINEC score PCT low risk group in comparison to $(11.26 \pm 5.09)$ LRINEC CRP low risk group, $(11.17 \pm 6.06)$ similar mean duration of stay in moderate risk group in both the score groups, whereas mean duration of stay in high risk LRINEC PCT group was $(14.93 \pm 5.64)$ in comparison to LRINEC CRP high group was $(13.17 \pm 5.56)$ as shown in Table 4.

LRINEC score PCT had better predictability for severity and duration of hospital stay when compared to LRINEC score with CRP, Pearson correlation of LRINEC score PCT vs. LRINEC score CRP was statistically significant with LRINEC score PCT having $30 \%$ of patients with longer duration of hospital stay in comparison to LRINEC score CRP, which had $12 \%$. (P value $<0.001)$.

\begin{tabular}{|c|c|c|c|c|}
\hline \multirow{2}{*}{ Age in Years } & \multicolumn{3}{|c|}{ LRINEC PCT } & \multirow{2}{*}{ Total } \\
\hline & Low Risk & Moderate Risk & High Risk & \\
\hline $20-30$ & $1(4.3 \%)$ & $1(8.3 \%)$ & $1(6.7 \%)$ & $3(6 \%)$ \\
\hline $31-40$ & $3(13 \%)$ & $0(0 \%)$ & $1(6.7 \%)$ & $4(8 \%)$ \\
\hline $41-50$ & $4(17.4 \%)$ & $4(33.3 \%)$ & $4(26.7 \%)$ & $12(24 \%)$ \\
\hline $51-60$ & $4(17.4 \%)$ & $2(16.7 \%)$ & $1(6.7 \%)$ & $7(14 \%)$ \\
\hline $61-70$ & $7(30.4 \%)$ & $0(0 \%)$ & $5(33.3 \%)$ & $12(24 \%)$ \\
\hline $71-80$ & $4(17.4 \%)$ & $4(33.3 \%)$ & $2(13.3 \%)$ & $10(20 \%)$ \\
\hline$>80$ & $0(0 \%)$ & $1(8.3 \%)$ & $1(6.7 \%)$ & $2(4 \%)$ \\
\hline Total & $23(100 \%)$ & $12(100 \%)$ & $15(100 \%)$ & $50(100 \%)$ \\
\hline \multirow{2}{*}{ Age in Years } & \multicolumn{3}{|c|}{ LRINEC PCT } & \multirow{2}{*}{ Total } \\
\hline & Low Risk & Moderate Risk & High Risk & \\
\hline $20-30$ & $1(4.3 \%)$ & $1(8.3 \%)$ & $1(6.7 \%)$ & $3(6 \%)$ \\
\hline $31-40$ & $3(13 \%)$ & $0(0 \%)$ & $1(6.7 \%)$ & $4(8 \%)$ \\
\hline $41-50$ & $4(17.4 \%)$ & $4(33.3 \%)$ & $4(26.7 \%)$ & $12(24 \%)$ \\
\hline $51-60$ & $4(17.4 \%)$ & $2(16.7 \%)$ & $1(6.7 \%)$ & $7(14 \%)$ \\
\hline $61-70$ & $7(30.4 \%)$ & $0(0 \%)$ & $5(33.3 \%)$ & $12(24 \%)$ \\
\hline $71-80$ & $4(17.4 \%)$ & $4(33.3 \%)$ & $2(13.3 \%)$ & $10(20 \%)$ \\
\hline$>80$ & $0(0 \%)$ & $1(8.3 \%)$ & $1(6.7 \%)$ & $2(4 \%)$ \\
\hline Total & $23(100 \%)$ & $12(100 \%)$ & $15(100 \%)$ & $50(100 \%)$ \\
\hline \multicolumn{5}{|c|}{ Table 2: Age Distribution of Patients Studied in Relation to LRINEC - PCT and LRINEC - CRP } \\
\hline
\end{tabular}

\begin{tabular}{|c|c|c|}
\hline Serum & $\begin{array}{c}\text { No. of Patients } \\
(\mathbf{n = 5 0})\end{array}$ & \% \\
\hline PCT & 25 & \\
\hline$\bullet \quad$ Negative & 25 & 50.0 \\
\hline$\bullet \quad$ Positive & 38 & 50.0 \\
\hline CRP & Negative & 76.0 \\
\hline$\bullet \quad$ Positive & Table 3: Serum PCT and CRP \\
\hline \multicolumn{2}{|c|}{} \\
\hline \multicolumn{2}{|c|}{} \\
\hline
\end{tabular}

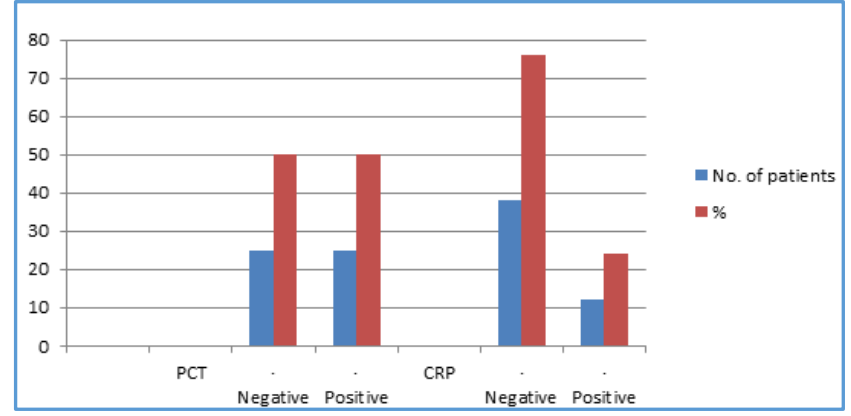

Graph: Showing Comparison of PCT and CRP

\begin{tabular}{|c|c|c|c|c|c|}
\hline & \multicolumn{3}{|c|}{ LRINEC-PCT } & \multirow{2}{*}{ Total } & \multirow{2}{*}{ P value } \\
\hline & Low Risk & Moderate Risk & High Risk & & \\
\hline \multirow[t]{3}{*}{ Duration of stay (days) } & $9.70 \pm 4.02$ & $11.17 \pm 6.06$ & $14.93 \pm 5.64$ & $11.62 \pm 5.45$ & $0.011^{*}$ \\
\hline & \multicolumn{3}{|c|}{ LRINEC-CRP } & \multirow{2}{*}{ Total } & \multirow{2}{*}{ P value } \\
\hline & Low Risk & Moderate Risk & High Risk & & \\
\hline Duration of stay (days) & $11.26 \pm 5.09$ & $11.77 \pm 6.50$ & $13.17 \pm 5.56$ & $11.62 \pm 5.45$ & 0.738 \\
\hline
\end{tabular}

\section{DISCUSSION}

Necrotizing fasciitis is associated with high mortality rates. It is very important to recognize the condition early and to initiate early empirical antibiotics and early surgical debridement to prevent complications and to reduce mortality.

In our study almost all patients presented with local tenderness $(100 \%)$, oedema $(100 \%)$, erythema $(100 \%)$ and swelling (100\%); similar to the findings of $\mathrm{P}$ Kumar et al in 2016.15 Majority of patients with necrotizing fasciitis had lower limb involvement, overall $86 \%$ similar to those of a study done by C P Garg et al in 2009.16

This is the first study comparing LRINEC score PCT with LRINEC score CRP with respect to duration of hospital stay and severity of infection. Maximum duration of hospital stay being 30 days and minimum duration of stay was 5 days and the 
mean duration of stay was $(9.70 \pm 4.02) ; 88 \%$ of the patients had early initiation of antibiotics and $76 \%$ had surgical debridement within 72 hours of admission. Despite early initiation of antibiotics and early debridement patient with high LRINEC score PCT had longer duration of stay.

The early initiation of antimicrobial therapy, fluid and electrolyte management and surgical debridement with wound care and prevention of organ failure has markedly reduced the mortality in necrotizing soft tissue infections. ${ }^{17}$

Drawbacks of the studies were it was a retrospective study and study sample size was small. To maintain the uniformity, we did not include patients who expired, the mortality rate is very high in necrotizing fasciitis mortality rate would have given a still better picture. From our study, we conclude that LRINEC score PCT had better probability in predicting severity and duration of hospital stay when compared LRINEC score CRP.

\section{CONCLUSION}

LRINEC score PCT had better probability in predicting severity and duration of hospital stay when compared LRINEC score CRP.

\section{REFERENCES}

1. Jones J. Observations upon the losses of the confederate armies from battle, wounds and disease during the American civil war of 1861-1865, with investigations upon the number and character of the diseases supervening upon gun-shot wounds. The Richmond and Louisville Med J 1869;8:340-58.

2. Meleney FL. Haemolytic streptococcus gangrene. Arch Surg 1924;9(2):317-64.

3. Patino JF, Castro D. Necrotizing lesions of soft tissues: a review. World J Surg 1991;15(2):235-9.

4. Green RJ, Dafoe DC, Raffin TA. Necrotizing fasciitis. Chest 1996;110(1):219-29.

5. Dellinger EP. Severe necrotizing soft-tissue infections: multiple disease entities requiring a common approach. JAMA 1981;246(15):1717-21.
6. Wilson B. Necrotizing fasciitis. American Surgeon 1952;18(4):416-31.

7. Simonsen ESM, van Orman ER, Hatch BE, et al. Cellulitis incidence in a defined population. Epidemiol Infect 2006;134(2):293-9.

8. Wall DB, Klein SR, Black S, et al. A simple model to help distinguish necrotizing fasciitis from non-necrotizing soft tissue infection. J Am Coll Surg 2000;191(3):227-31.

9. Wong $\mathrm{CH}$, Khin $\mathrm{LW}$, Heng $\mathrm{KS}$, et al. The LRINEC (laboratory risk indicator for necrotizing fasciitis) score: a tool for distinguishing necrotizing fasciitis from other soft tissue infections. Crit Care Med 2004;32(7):1535-41.

10. Singh G, Sinha SK, Adhikary S, et al. Necrotising infections of soft tissues: a clinical profile. Eur J Surg 2002;168(6):366-71.

11. Singh G, Ray P, Sinha SK, et al. Bacteriology of necrotizing infections of soft tissues. Aust N Z J Surg 1996;66(11):747-50.

12. Anaya DA, McMahon $K$, Nathens AB, et al. Predictors of mortality and limb loss in necrotizing soft tissue infections. Arch Surg 2005;140(2):151-7.

13. Childers BJ, Potyondy LD, Nachreiner R, et al. Necrotizing fasciitis: a fourteen-year retrospective study of 163 consecutive patients. Am Surg 2002;68(2):109-16.

14. Su YC, Chen HW, Hong YC, et al. Laboratory risk indicator for necrotising fasciitis score and the outcomes. ANZ J Surg 2008;78(11):968-72.

15. Kumar PM, Kavitha K, Aneesh, et al. The role of empirical antibiotic therapy in treating necrotizing fasciitis: a retrospective record analysis. International Journal of Contemporary Medical Research 2016;3(5):1481-4.

16. Garg CP, Patel RN, Patel DN, et al. Necrotizing fasciitis: a prospective clinical study. Guj Med Journal 2009;64(2):55-8.

17. Mills MK, Faraklas I, Davis C, et al. Outcomes from treatment of necrotizing soft-tissue infections: results from the national surgical quality improvement program database. American Journal of Surgery 2010;200(6):790-7. 